\title{
The influence of different dietary energy concentrations on the production parameters of feedlot ostriches
}

\author{
T. S. Brand ${ }^{1,2, \#}$, S.F. Viviers ${ }^{2}$, J. van der Merwe ${ }^{2}$ \& L.C. Hoffman ${ }^{2}$ \\ ${ }^{1}$ Directorate: Animal Sciences, Department of Agriculture, Western Cape Government, Private Bag X1, Elsenburg, 7607, \\ South Africa \\ ${ }^{2}$ Department of Animal Sciences, University of Stellenbosch, Private Bag X1, Matieland, 7602, South Africa
}

(Received 21 June 2017; Accepted 10 October 2017; First published online 1 December 2017)

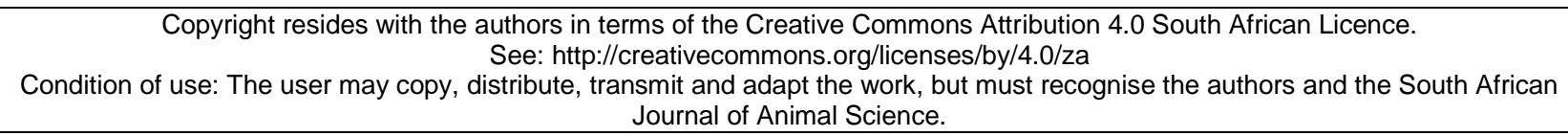

\begin{abstract}
Energy is essential for the continuous survival of any living organism. In ostrich diets, energy is usually derived from maize, which is often subject to fluctuations in yield as a result of drought conditions. Therefore, the optimal utilization of energy in the diets of ostriches becomes of paramount importance, but without affecting the performance of the birds negatively. This study was conducted to investigate the influence of five treatment diets, each with a different energy concentration, on the growth performance of 300 slaughter ostriches. Three replications per treatment resulted in 15 camps of ostriches being fed through the four feeding phases from pre-starter to starter, then grower, and finally finisher. A high mortality rate was experienced during the pre-starter phase, while the chicks were still young. Significant differences were found among the live weights of the birds after the pre-starter phase, with birds that consumed the middle diet (Diet 3) being the heaviest, at an average of $22.3 \pm 0.33 \mathrm{~kg}$. However, by the end of the trial, these differences were not significant. This was reflected in the production parameters, namely dry matter intake (DMI), average daily gain (ADG) and feed conversion ratio (FCR). Differences were found only in the prestarter phase in ADG, with Diet 3 displaying the highest gain per day of $216.0 \pm 8.08 \mathrm{~g}$. Thus, in this study, dietary energy above and below the predicted optimum (Diet 3) seemed to have little influence on the performance of the ostriches, but results may have been affected by the above-average mortalities.
\end{abstract}

Keywords: Average daily gain, dry matter intake, energy, feed conversion ratio, growth performance, ostrich nutrition

\#Corresponding author: tersb@elsenburg.com

\section{Introduction}

The ostrich (Struthio camelus var. domesticus) is the largest of the ratites, and is of paramount importance to many livestock industries owing to its healthy red meat and valuable skin, which is used for leather (Cooper \& Hornbañczuk, 2002). This applies to South Africa in particular, which is seen as the world leader in ostrich products, with approximately $70 \%$ of all ostrich meat, feathers and leather (Brand \& Jordaan, 2011) being produced in South Africa. Recently, the industry received a substantial boost from the decision by the European Union (EU) to lift the four-year ban on the export of raw ostrich meat from South Africa. Initially, the meat sector incurred a significant knock with a decrease in the number of birds slaughtered in 2011 of $~ 50 \%$ (Vecchiato, 2015), and profit margins became increasingly tighter, with many producers being forced to exit the industry. With exports set to resume, producers may feel optimistic about an extra avenue of supply for ostrich meat to overseas consumers, in addition to the pre-cooked market, which was established in the four-year isolation period to mitigate the effects of the ban on raw meat products.

However, although the markets for products from an ostrich system may look positive, the feeding of the birds remains an overhead concern, contributing $70-80 \%$ of the input costs (Brand et al., 2000). Therefore, the nutritional requirements of ostriches must be optimized to decrease feed costs (Kritzinger, 2011). A compounding factor producers need to consider is that maize meal is often the primary energy source in ostrich rations (Brand, 2007), and its price is heavily dependent on precipitation figures during the rainfall season. In addition, the growth of the human population brings the ethical consideration of whether 
feeding energy sources to livestock that are suitable for humans, is acceptable. Producers are concerned with knowledge that relates to optimum levels of energy in the diets without compromising the product quality.

Previous work by Brand et al. (2000) was conducted to assess the impact of three different dietary energy levels on certain production parameters of ostriches. In this study five different dietary energy levels were used to collect data to be able to explain certain tendencies with regard to the effect of dietary energy level on certain production parameters as well as certain end products. Thus, the effects of the treatment diets on the growth response of the chicks through to slaughter were analysed. This encompassed production parameters such as feed intake, ADG, and FCR. The effect of dietary energy on the abdominal fat pad was investigated because a theory postulated by Hoffman et al. (2005) suggested that the extra energy in the diet was stored there, and not in the intra-muscular fat reserves. In 2014, Brand et al. investigated the influence of diets with different dietary energy concentrations on production parameters in various phases. These studies concluded that DMI and ADG were not influenced by the energy concentration in the pre-starter phase, but FCR was significant lower (better) for a medium-energy diet that was similar to commercial feeds. In the starter phase, feed intakes and ADG were highest for the mediumenergy diet and FCR was lowest for the high-energy diet. In the grower phase, feed intake was not influenced by the diet. However, ADG was the highest for the medium-energy diet, while FCR was the lowest for this diet. Only ADG was influenced in the finisher phase. The high energy diet resulted in the highest ADG (Brand et al., 2014).

\section{Materials and methods}

The trial was conducted at Kromme Rhee Research Farm of the Western Cape Department of

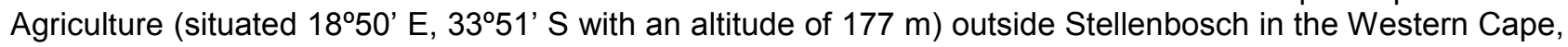
South Africa. The trial period extended from December 2013 to December 2014, incorporating full seasonal changes over a year. The experiment was designed with five treatment diets with varying energy concentrations for each of the four physiological feeding phases associated with ostrich production.

The diets after chemical analysis that were available to the birds throughout the trial are presented in Tables 1 and 2.

Table 1 Analysis (as is basis) of experimental diets containing five levels of energy $(1,2,3,4$, and 5$)$ fed to ostriches during the pre-starter ( $0-83$ days) and starter (84-149 days) phases

\begin{tabular}{|c|c|c|c|c|c|c|c|c|c|c|}
\hline \multirow{3}{*}{ Nutrient } & \multicolumn{10}{|c|}{ Diet number } \\
\hline & \multicolumn{5}{|c|}{ Pre-starter } & \multicolumn{5}{|c|}{ Starter } \\
\hline & 1 & 2 & 3 & 4 & 5 & 1 & 2 & 3 & 4 & 5 \\
\hline $\mathrm{ME}^{*} \mathrm{MJ} / \mathrm{kg}$ feed $^{1}$ & 13.5 & 14.0 & 14.5 & 15.0 & 15.5 & 12.5 & 13.0 & 13.5 & 14.0 & 14.5 \\
\hline Dry material $(\mathrm{g} / \mathrm{kg})$ & 904.7 & 899.1 & 905.7 & 905.8 & 909.6 & 885.4 & 881.2 & 884.7 & 856.3 & 899.3 \\
\hline Crude protein $((\mathrm{g} / \mathrm{kg})$ & 170.6 & 179.2 & 184.7 & 181.8 & 191.9 & 174.8 & 179.2 & 182.7 & 181.1 & 190.1 \\
\hline Ash $(\mathrm{g} / \mathrm{kg})$ & 78.1 & 78.6 & 80.9 & 80.7 & 84.3 & 79.5 & 77.8 & 76.8 & 74.4 & 80.6 \\
\hline IVOMD $^{2}(\mathrm{~g} / \mathrm{kg})$ & 790.3 & 802.5 & 818.6 & 863.2 & 872.1 & 774.7 & 780.7 & 822.5 & 834.7 & 843.8 \\
\hline Crude fibre $(\mathrm{g} / \mathrm{kg})$ & 85.0 & 76.4 & 71.5 & 57.5 & 53.9 & 101.3 & 89.6 & 77.1 & 72.2 & 69.9 \\
\hline Fat $(\mathrm{g} / \mathrm{kg})$ & 30.0 & 39.7 & 53.6 & 62.3 & 70.1 & 27.2 & 39.8 & 46.5 & 50.9 & 52.5 \\
\hline $\operatorname{ADF}^{* *}(\mathrm{~g} / \mathrm{kg})$ & 98.4 & 90.3 & 77.5 & 55.5 & 58.5 & 119.6 & 99.3 & 89.9 & 79.9 & 68.7 \\
\hline $\operatorname{NDF}^{* * *}(\mathrm{~g} / \mathrm{kg})$ & 260.8 & 245.0 & 212.1 & 194.1 & 167.0 & 274.6 & 238.8 & 231.5 & 205.3 & 194.3 \\
\hline Calcium (g/kg) & 12.4 & 12.2 & 12.6 & 13.3 & 13.4 & 12.4 & 12.5 & 12.3 & 12.8 & 12.1 \\
\hline Phosphorous (g/kg) & 7.6 & 7.7 & 8.1 & 7.5 & 8.0 & 7.4 & 7.7 & 7.6 & 7.4 & 7.2 \\
\hline
\end{tabular}

\footnotetext{
As formulated
${ }_{2}$ In vitro organic matter digestibility

* $\mathrm{ME}=$ metabolizable energy

${ }^{* *} \mathrm{ADF}=$ average daily gain

${ }^{* * *} \mathrm{NDF}=$ neutral detergent fibre
} 
Table 2 Analysis (as is basis) of experimental diets containing five levels of energy (1, 2, 3, 4, and 5) fed to ostriches during the grower (150-228 days) and finisher (229-344 days) phases

\begin{tabular}{|c|c|c|c|c|c|c|c|c|c|c|}
\hline \multirow{3}{*}{ Nutrient } & \multicolumn{10}{|c|}{ Diet number } \\
\hline & \multicolumn{5}{|c|}{ Grower } & \multicolumn{5}{|c|}{ Finisher } \\
\hline & 1 & 2 & 3 & 4 & 5 & 1 & 2 & 3 & 4 & 5 \\
\hline $\begin{array}{l}\text { ME }{ }^{*} \mathrm{MJ} / \mathrm{kg} \text { feed }{ }^{1} \\
\text { Dry material }(\mathrm{g} / \mathrm{kg})\end{array}$ & $\begin{array}{r}10.5 \\
901.2\end{array}$ & $\begin{array}{r}11.0 \\
896.1\end{array}$ & $\begin{array}{r}11.5 \\
896.5\end{array}$ & $\begin{array}{r}12.0 \\
895.6\end{array}$ & $\begin{array}{r}12.5 \\
893.3\end{array}$ & $\begin{array}{r}9.5 \\
885.9\end{array}$ & $\begin{array}{r}10.0 \\
879.0\end{array}$ & $\begin{array}{r}10.5 \\
892.9\end{array}$ & $\begin{array}{r}11.0 \\
883.8\end{array}$ & $\begin{array}{r}11.5 \\
884.7\end{array}$ \\
\hline Crude protein $(\mathrm{g} / \mathrm{kg})$ & 148.4 & 153.2 & 155.3 & 143.0 & 137.2 & 142.8 & 143.4 & 154.2 & 166.3 & 180.3 \\
\hline Ash $(\mathrm{g} / \mathrm{kg})$ & 80.5 & 81.7 & 83.2 & 81.7 & 76.8 & 96.7 & 94.6 & 93.1 & 99.6 & 103.3 \\
\hline IVOMD $^{2}(\mathrm{~g} / \mathrm{kg})$ & 708.6 & 720.2 & 752.7 & 793.4 & 811.2 & 605.5 & 631.6 & 709.0 & 725.3 & 768.8 \\
\hline Crude fibre $(\mathrm{g} / \mathrm{kg})$ & 210.3 & 172.8 & 147.9 & 122.6 & 102.1 & 158.5 & 156.6 & 154.2 & 150.9 & 131.4 \\
\hline Fat $(\mathrm{g} / \mathrm{kg})$ & 16.7 & 20.5 & 19.8 & 19.6 & 21.1 & 14.3 & 15.3 & 16.0 & 19.4 & 19.3 \\
\hline $\operatorname{ADF}^{* *}(g / k g)$ & 229.9 & 211.4 & 179.5 & 148.1 & 118.0 & 196.3 & 191.7 & 179.1 & 176.8 & 167.0 \\
\hline $\operatorname{NDF}^{* 1 *}(g / k g)$ & 335.9 & 307.5 & 293.3 & 261.7 & 221.7 & 381.0 & 356.5 & 325.2 & 308.1 & 297.4 \\
\hline Calcium (g/kg) & 12.1 & 13.0 & 13.0 & 13.6 & 14.3 & 15.9 & 18.1 & 14.7 & 13.0 & 12.6 \\
\hline Phosphorous (g/kg) & 6.9 & 6.9 & 7.0 & 6.8 & 0.72 & 9.6 & 8.9 & 8.6 & 6.8 & 6.5 \\
\hline \multicolumn{11}{|c|}{$\begin{array}{l}\text { As formulated } \\
{ }^{2} \text { In vitro organic matter digestibility } \\
\text { 'ME: metabolizable energy }\end{array}$} \\
\hline
\end{tabular}

Each treatment diet was replicated three times, yielding 15 camps of ostriches in total, with an average of 16 chicks per camp. The treatment diets were labelled Diets 1,2, 3, 4 and 5, with increasing energy concentration in each. Diet 3 was formulated to contain standard energy concentration (pre-starter: 14.5 MJ ME/kg; starter: 13.5 MJ ME/kg; grower: 11.5 MJ ME/kg; finisher: $10.5 \mathrm{MJ} \mathrm{ME} / \mathrm{kg}$ ) used in the industry. The remaining treatment diets were formulated to contain energy levels of $0.5 \mathrm{MJ} \mathrm{ME} / \mathrm{kg}$ and $1 \mathrm{MJ}$ $\mathrm{ME} / \mathrm{kg}$, lower and higher than that of the standard energy concentration for each feeding phase, (Diets 2 and 4; and Diets 1 and 5, respectively) (Tables 1 and 2). For ease of identification and clarity, this system will be employed throughout the results and discussion.

The chicks were initially kept indoors with free access to outdoors during the day, but closed up at night for protection against the elements. They were then moved into larger outdoor camps at 10 weeks old to prevent excessive skin damage. These outdoor camps, with approximate dimensions of $25 \mathrm{~m} \times 20 \mathrm{~m}$, contained adequate shelter for the ostriches and cover for the feed troughs from exposure to moisture from dew and rainfall. The birds received their treatment diets ad libitum, and had constant access to fresh clean water.

Initially, the birds were weighed three times a week until they were moved into the outdoor camps. From then, until the commencement of the finisher phase, they were weighed twice a week. During the finisher phase they were weighed once weekly because of the increased difficulty in handling them as a result of weight gain. The ADGs throughout the trial were determined. The ADG was calculated as the live weight of the bird at the end of the trial minus the live weight at the onset, divided by the number of days on the feed. Feed refusals were weighed once weekly to determine the intake per camp, and subsequently it was possible to calculate FCR (FCR = feed intake divided by ADG).

A high mortality rate of $36 \%$ was experienced across all diets, particularly in the pre-starter phase of the trial, as a result of unseasonal cold spells. At 12 months old, the birds were placed in quarantine camps, as stipulated by EU meat quality standards in the report by the Department of Agriculture (DAFF, 2013), where they continued to receive their treatment diets. Routine testing for Avian Influenza (Al) was conducted as stipulated by the EU to determine the Al status of the farm before the birds were presented for slaughter. Initial results indicated that possible strains of the virus were present in some of the birds, which prompted further blood collection and testing. The follow-up results yielded negative polymerase-chain reaction and no active circulation of the virus, as confirmed by the serology report. However, procedures for such an event 
resulted in the need to slaughter the birds under a red cross permit, issued by a state veterinarian, because the farm had been placed under temporary quarantine.

A private contractor was hired to transport the ostriches approximately $50 \mathrm{~km}$ to the Swartland abattoir in Malmesbury. The maximum capacity in this particular vehicle was 80 ostriches. Therefore transport was completed in two trips. The birds were offloaded in a lairage area designed to receive ostriches, with a supply of fresh clean water. The birds were kept in lairage overnight for approximately 18 hours before slaughter commenced early the following morning. The slaughter procedures were comparable with those depicted by Hoffman (2012).

Each bird was weighed immediately before slaughter to give an accurate indication of the final weight at slaughter. After exsanguination, each bird was marked to ensure that there was no confusion during the collection of the feathers. Next, individual skins were removed and marked before being prepared for further processing. Following evisceration, the abdominal fat, commonly referred to as the fat pad, was collected and weighed for each bird to determine whether the dietary energy had any effect on the yields.

The carcasses, which consisted of the neck, wings, chest and thighs, were washed, and their weights were recorded to give the warm carcass yield before they were moved into the cold storage facility. The carcasses were then transported to Mosstrich Abattoir in Mossel Bay for the collection of data after they had been kept in a cold chamber at Swartland Abattoir for 60 hours because the slaughter date fell at the end of the working week. Dressing percentages were determined using cold carcass weight as a proportion of live weight at slaughter.

Statistical analysis was done with SAS Enterprise Guide (version 9.2). A regression analysis was done per treatment diet over age to assess the weight gains by the birds. Various growth models were investigated and Gompertz curves yielded the best fit. This Gompertz model was used: bird mass $=\mathrm{a}^{*} \exp (-$ $\exp \left(-b^{*}(\right.$ Age-c) $\left.)\right)$, where $a=$ maximum weight $(\mathrm{kg}), b=$ rate of maturing, and $c=$ age of maximum growth (days). The slopes were then compared to assess differences in weight gain using analysis of variance (ANOVA). Regression was run per treatment over age in each feeding phase, and the slopes were compared per physiological phase. ANOVAs were conducted on predicted averages for the production parameters, namely DMI, ADG and FCR, as no distinct trends were observed in the slopes obtained per treatment. ANOVAs were then done on the parameters measured at slaughter such as the live weight, warm carcass weight, cold carcass weight, fat pad weight, right thigh weight, big drum (M. gastrocnemius) weight and dressing percentages.

\section{Results}

When the average weights of the birds were analysed at the end of each of the feeding phases, differences $(P<0.05)$ were found among the treatments after the pre-starter phase (Table 3$)$. However, only the birds fed Diet 5 had lighter $(P<0.05)$ weights $(10.9 \pm 0.56 \mathrm{~kg})$ in comparison with those fed the other four treatment diets. During the rest of the trial period, no differences $(P>0.05)$ were found at the end of the remaining phases among the weights of the birds.

Table 3 Least square means and root mean square error of the live weights for effect of dietary energy concentrations on phase by phase growth of slaughter ostriches

\begin{tabular}{lccccccc}
\hline $\begin{array}{l}\text { Mean weight (kg) at end of } \\
\text { (age): }\end{array}$ & $\mathbf{1}$ & $\mathbf{2}$ & $\mathbf{3}$ & $\mathbf{4}$ & $\mathbf{5}$ & RMSE & P-value \\
\cline { 2 - 6 } & $18.9^{\mathrm{a}}$ & $21.7^{\mathrm{a}}$ & $22.3^{\mathrm{a}}$ & $19.6^{\mathrm{a}}$ & $10.9^{\mathrm{b}}$ & 2.365 & 0.006 \\
Pre-starter (0-83 days) & 44.8 & 50.2 & 51.5 & 46.3 & 39.6 & 3.972 & 0.066 \\
Starter (84-149 days) & 69.6 & 77.0 & 78.8 & 77.0 & 68.1 & 5.053 & 0.145 \\
Grower (150-228 days) & 102.2 & 108.5 & 109.4 & 108.6 & 97.2 & 4.948 & 0.110 \\
Finisher (229-344 days) & & & & &
\end{tabular}

${ }^{\mathrm{a}, \mathrm{b}}$ Values within a row with different superscripts differ significantly at $P<0.05$.

RMSE: root mean square error

With regard to the Gompertz model parameters, no differences $(P>0.05)$ were found across the three parameters (Table 4). The maximum weight achievable ( $\mathrm{kg}$ ) was denoted by the letter ' $a$ ', while ' $b$ ' was a measure of the rate of maturity of the birds, and ' $c$ ' was the age at which the birds achieved their maximum growth rate in days. 
Table 4 Growth parameters and root mean square error of slaughter ostriches as predicted by the Gompertz growth curve

\begin{tabular}{|c|c|c|c|c|c|c|c|}
\hline \multirow{2}{*}{ Gompertz model parameters } & \multicolumn{5}{|c|}{ Diet } & \multirow[b]{2}{*}{ RMSE } & \multirow[b]{2}{*}{ P-value } \\
\hline & 1 & 2 & 3 & 4 & 5 & & \\
\hline a & 107.8 & 115.3 & 115.8 & 118.2 & 105.8 & 7.042 & 0.317 \\
\hline b & 0.0107 & 0.0110 & 0.0114 & 0.0106 & 0.0117 & 0.001 & 0.640 \\
\hline c & 141.1 & 132.9 & 132.4 & 141.9 & 150.0 & 8.790 & 0.251 \\
\hline
\end{tabular}

a: maximum weight $(\mathrm{kg}), \mathrm{b}$ : rate of maturing parameter, c: age of maximum growth (days)

RMSE: root mean square error

The production parameters measured during the trial are presented in Table 5 for each phase, and for the overall trial period. The only differences were between the ADGs attained by the chicks during the prestarter phase. The chicks fed the intermediary Diets 2,3 and 4 had significantly $(P<0.05)$ higher daily gains than those exposed to the two extreme diets, namely the lowest energy diet (1) and highest energy diet (5). The chicks that received Diet 3 displayed the highest daily gains of $216.0 \pm 8.08 \mathrm{~g}$ per day, while those fed Diet 5 had the lowest daily gains of $137.5 \pm 11.3 \mathrm{~g}$ per day.

None of the other phases yielded differences $(P>0.05)$ for any of the parameters (Table 5$)$.

Table 5 Least square means and root mean square error for the effect of dietary energy concentrations on the production parameters of slaughter ostriches

\begin{tabular}{|c|c|c|c|c|c|c|c|}
\hline \multirow{2}{*}{ Parameter } & \multicolumn{5}{|c|}{ Diet } & \multirow[b]{2}{*}{ RMSE } & \multirow[b]{2}{*}{$\begin{array}{c}P \text { - } \\
\text { value }\end{array}$} \\
\hline & 1 & 2 & 3 & 4 & 5 & & \\
\hline \multicolumn{8}{|c|}{ Dry matter intake (DMI) (kg/bird/day) } \\
\hline All phases & 2.03 & 1.83 & 1.89 & 1.74 & 1.62 & 0.237 & 0.455 \\
\hline Pre-starter & 0.31 & 0.36 & 0.34 & 0.35 & 0.21 & 0.063 & 0.198 \\
\hline Starter & 1.30 & 1.07 & 1.23 & 1.22 & 1.20 & 0.200 & 0.722 \\
\hline Grower & 2.22 & 2.10 & 2.25 & 2.18 & 2.24 & 0.345 & 0.984 \\
\hline Finisher & 3.65 & 3.22 & 3.21 & 2.80 & 2.52 & 0.511 & 0.237 \\
\hline \multicolumn{8}{|c|}{ Average daily gain (ADG) (g/bird/day) } \\
\hline All phases & 280.0 & 304.9 & 307.2 & 302.0 & 277.2 & 14.924 & 0.130 \\
\hline Pre-starter & $171.6^{\mathrm{ab}}$ & $212.0^{\mathrm{C}}$ & $216.0^{c}$ & $192.8^{\mathrm{bc}}$ & $137.5^{\mathrm{a}}$ & 16.799 & 0.005 \\
\hline Starter & 381.1 & 428.1 & 444.0 & 414.3 & 370.0 & 34.374 & 0.164 \\
\hline Grower & 396.1 & 419.5 & 423.3 & 423.3 & 415.6 & 26.096 & 0.709 \\
\hline Finisher & 219.1 & 223.3 & 216.1 & 233.3 & 229.0 & 25.040 & 0.937 \\
\hline \multicolumn{8}{|c|}{ Feed conversion ratio (FCR) ( $\mathrm{kg}$ feed/kg weight gain) } \\
\hline All phases & 8.59 & 7.46 & 7.72 & 6.54 & 6.24 & 1.221 & 0.301 \\
\hline Pre-starter & 1.53 & 1.51 & 1.47 & 1.63 & 1.54 & 0.262 & 0.973 \\
\hline Starter & 3.51 & 2.52 & 2.75 & 2.95 & 3.24 & 0.617 & 0.397 \\
\hline Grower & 5.70 & 5.10 & 5.41 & 5.19 & 5.43 & 0.636 & 0.817 \\
\hline Finisher & 16.59 & 14.19 & 14.64 & 11.04 & 9.89 & 3.542 & 0.308 \\
\hline
\end{tabular}

${ }^{a, b, c}$. Values within a row with different superscripts differ significantly at $P<0.05$

RMSE: root mean square error 
In terms of the parameters measured before and post slaughter, no differences $(P>0.05)$ were found (Table 6). However, focusing on live weight measured just before slaughter, significance was approached $(P$ $=0.06$ ), but fell just outside the bounds used for significance (95\%). The birds fed Diet 3 yielded the heaviest live weights, at an average of $110.1 \pm 3.50 \mathrm{~kg}$, while the birds exposed to Diet 5 were the lightest at $97.1 \pm$ $3.35 \mathrm{~kg}$.

Table 6 Least square means and root mean square error for the effect of dietary energy concentrations on slaughter parameters for slaughter ostriches

\begin{tabular}{|c|c|c|c|c|c|c|c|}
\hline \multirow{2}{*}{ Parameters } & \multicolumn{5}{|c|}{ Diets } & \multirow[b]{2}{*}{ RMSE } & \multirow[b]{2}{*}{$\begin{array}{c}\text { P- } \\
\text { value }\end{array}$} \\
\hline & 1 & 2 & 3 & 4 & 5 & & \\
\hline Live weight (kg) & 99.0 & 108.2 & 110.1 & 102.0 & 97.1 & 5.129 & 0.064 \\
\hline Warm carcass $(\mathrm{kg})$ & 48.5 & 53.8 & 52.3 & 48.1 & 45.4 & 3.497 & 0.124 \\
\hline Cold carcass (kg) & 45.5 & 50.7 & 49.6 & 45.0 & 42.6 & 3.438 & 0.114 \\
\hline Dressing percentage (\%) & 46.0 & 46.9 & 45.2 & 43.6 & 43.9 & 2.121 & 0.378 \\
\hline Right thigh weight (kg) & 16.9 & 18.6 & 18.1 & 16.3 & 15.9 & 1.266 & 0.150 \\
\hline Right thigh percentage of carcass (\%) & 37.1 & 36.7 & 36.5 & 36.3 & 37.1 & 0.434 & 0.178 \\
\hline Abdominal fat pad (kg) & 5.11 & 5.06 & 6.16 & 4.56 & 6.02 & 1.447 & 0.661 \\
\hline M. gastrocnemius (big drum) weight (kg) & 1.04 & 1.20 & 1.12 & 0.99 & 1.01 & 0.086 & 0.090 \\
\hline M. gastrocnemius percentage of thigh (\%) & 6.14 & 6.35 & 6.18 & 6.01 & 6.30 & 0.242 & 0.514 \\
\hline
\end{tabular}

\section{Discussion}

The results achieved by the ostriches in terms of growth are highlighted in Table 3. Slight differences in liveweight were observed across the four feeding stages, when the weights of the birds were compared at the end of each phase. Only after the pre-starter phase were the differences found to be significant, with the birds fed Diet 5 being substantially lighter than their counterparts at the same stage. The birds in Diet 5 were fed at an energy level of $15.5 \mathrm{MJ} \mathrm{ME} / \mathrm{kg}$ feed, and attained similar weights to birds fed at the same energy content in a study by Brand et al. (2014). Their difference from the rest of the treatment groups may have been influenced by the high mortality rate in one of the replications of birds fed Diet 5 . Furthermore, the high mortality rate across the whole trial may have had a negative impact on the results obtained for the whole period by magnifying the variation among the birds.

The Gompertz parameters in Table 4 support the results of the weights of the birds at the end of the trial in which no differences were reported. The parameter (b), which measured the rate of maturity of the birds, showed no differences; nor did the age at which the birds were predicted to reach maximum growth (c).

The results reported thus far with regard to the growth of the birds fed the treatment diets are mirrored and are justified to a degree, when the findings of the production parameters are dissected (Table 5). Previous studies by Brand et al. (2000), Brand et al. (2004), and Glatz et al. (2008) tended to indicate differences when the influence of dietary energy on the production parameters was investigated. Therefore, the results obtained in this study may be contradictory to previous studies involving dietary energy concentrations, and may have been a result of the high mortality rate experienced during the pre-starter phase of the trial. The results, however, are consistent, as the differences in the growth of birds fed the respective treatment diets would inevitably translate into the trends observed across the production parameters, and vice versa.

Although no statistical differences were observed in intake, Diet 1 displayed a marginally higher intake value over the study. This could be because the birds attempted to compensate for decreased energy concentration with increased intake, while the birds that received Diet 5 required $\sim 20 \%$ less feed throughout the trial. Thus, an incremental increase in dietary energy content resulted in a corresponding decrease in DMI by $0.089 \mathrm{~kg}$. However, these findings were not significant $(P>0.05)$; thus a repetition of the trial may result in different findings and conclusions.

Except for the pre-starter phase, none of the phases yielded differences $(P>0.05)$ in DMI, ADG or FCR (Table 5). In the pre-starter phase, differences were attained among the ADGs $(P<0.05)$. The chicks 
that were fed on Diets 2, 3 and 4 had significantly higher daily gains than those exposed to Diets 1 and 5 . This highlights the importance of correct formulation of dietary energy content, because under- or oversupply resulted in marginally decreased performances.

None of the phases had a significant difference in the FCR values $(P>0.05)$ (Table 5). Importantly, the FCR values displayed in this study indicate the importance of the decision about when to slaughter the birds. For example, the FCR value during the finisher phase for Diet 3 was $14.64 \pm 1.42 \mathrm{~kg}$ feed per $\mathrm{kg}$ weight gain. Its viability therefore becomes a decision for the producer, in which the price of feeding the birds may be offset by the high cost of continued feeding.

Although no differences were found across the parameters measured before and post slaughter (Table 6), the $P$-value for the live weight of the ostriches approached significance $(P=0.06)$. Previous work by Glatz et al. (2008) and Brand et al. (2014) showed differences were present between the weights of the birds fed different levels of energy. Brand et al. (2014,) however, fed only three treatment diets during the finisher phase, with energy concentrations of $9.5,10.5$ and $11.5 \mathrm{MJ} \mathrm{ME} / \mathrm{kg}$ feed, whereas this study had two additional treatment diets. This may have contributed to the results in this study, which were similar to those of Brand et al. (2014). The two extra diets might have buffered the differences as the energy concentrations were $9.5,10.0,10.5,11.0$ and $11.5 \mathrm{MJ} \mathrm{ME} / \mathrm{kg}$ feed across the five diets. Similarly, the lower number of treatment replications (three as opposed to six replications) might have contributed to these results, which were compounded by a degree of variation in the treatment groups that influenced the deviations from the treatment means.

Interestingly, the losses observed from warm to cold carcasses in this study were abnormally high. No differences were evident for either parameter among the carcasses fed the various treatment diets, but the losses from warm carcass mass to those recorded on the cold carcass were $\sim 6 \%$. This was because the carcasses hung in cold storage for an extra 72 hours (above). These differences are approximately triple ( 2\%) of that reported by Hoffman et al. (2012), highlighting the losses that can be experienced as a result of hang time in the cold storage units. This had a knock-on effect on the dressing percentages, which were lower by $\sim 3 \%$ than those obtained by Brand et al. (2014) using ostriches slaughtered at a similar age.

No differences were found in thigh weights. This was expected, because no differences were evident between the cold carcasses. However, the thigh constitutes $(\sim 37 \%)$ a high proportion of the carcass Doubling this figure sheds light on the value that is placed on the thighs of ostriches, as they account for approximately $74 \%$ of an ostrich carcass.

No differences were found in the yields obtained for the abdominal fat pads in this study, (Table 6). Hoffman et al. (2005) investigated the possibility of excess dietary energy being stored as intra-muscular fat in the muscles of ostriches. However, they found no evidence of diet affecting the fat content in the muscles, postulating that excess energy might be converted and stored in the abdominal fat pad reserves. The findings in this study suggest that dietary energy has no effect on fat pad yields. Therefore the genetics of the birds may play a more significant role in the influence on the fat pads than nutrition, and may warrant further research to better understand the mechanisms.

\section{Conclusion}

The effects of dietary energy on production parameters such as DMI, ADG and FCR were investigated in this study. The high mortality rate experienced during the pre-starter phase of the trial may have contributed to findings that to an extent, contradictory to previous studies that investigated the impact of energy on production of ostriches. These mortalities were more common than is desired in ostriches, in which normal mortality rates are as high as 40\% (Brand \& Gous, 2006). Nevertheless, differences were minimal among the growth rates of the birds on the treatment diets, which was reflected in the production parameters that were measured. Energy also seemed to have a minimal effect on the fat pad yields harvested from the birds fed the various energy concentrations.

Energy sources, particularly maize, are set to increase in price, and producers have to consider carefully the stage at which they slaughter their ostriches. Continual feeding becomes risky because of the quantities of feed that are required to increase bodyweight. Thus, with the recent lifting of the ban on fresh meat exports to the EU, coupled with the increase in the price of maize as a result of the drought in South Africa, producers may contemplate slaughtering ostriches at a younger age. With lowest cost feed formulation and optimal nutrient requirements (Gous \& Brand, 2008) the 'ideal' slaughter weight and skin size are attainable at $85 \mathrm{~kg}$ live weight, which could be reached at 11 to 12 months old with sound feed management practices.

\section{Acknowledgements}

Acknowledgements are made to the Western Cape Department of Agriculture for joint funding of the study, and to the personnel in their employment for their aid; to Western Cape Agricultural Research Trust for the joint funding of the 
study; and to Swartland abattoir in Malmesbury and Mosstrich abattoir in Mossel Bay for their willingness to accommodate our needs during the slaughter process and subsequent data collection.

\section{Authors' Contributions}

Concept and design: TSB; data collection and analysis: SFV; drafting of paper: JvdM; critical revision and final approval of version to be published: LCH. This statement is to certify that all the authors of this paper made substantial contributions to conception and design, and/or acquisition of data, and/or analysis and interpretation of data. All the authors have seen and approved the manuscript being submitted.

\section{Conflict of Interest Declaration}

The authors certify that they have no affiliations with or involvement in any organization or entity with financial or non-financial interests in the subject matter and materials discussed in this manuscript.

\section{References}

Brand, T. \& Jordaan, J., 2011. The contribution of the South African ostrich industry to the national economy. Appl. Anim. Husb. Rural Develop. 4: 1-7.

Brand, T.S. 2007. Ostrich nutrition and management. Agriprobe 4: 17-18.Brand, T.S. \& Gous, R.M., 2006. Feeding ostriches. In: V. Bels (ed). Feeding in domestic vertebrates: From structure to behaviour, pp 136-155. CAB International, Wallingford, England.

Brand, T.S., Carstens, P.D. \& Hoffman, L.C., 2014. The effect of dietary energy concentrations on production variables of ostrich chicks (Struthio camelus var. domesticus) Brit. Poultry Sci. 55: 610-618.Brand, T.S., Nell, C. \& Van Schalkwyk, S. 2000. The effect of dietary energy and protein level on the production of growing ostriches. S. Afr. J. Anim. Sci. 30:15-16.

Brand, T.S., Gous, R., Horbañczuk, J., Kruger, A., Aucamp, B. \& Brand, Z., 2004. The effect of dietary energy and protein (amino acid) concentrations on the end products of slaughter ostriches. S. Afr. J. Anim. Sci. 34:107-109.

Cooper, R.G. \& Horbañczuk, J.O., 2002. Anatomical and physiological characteristics of ostrich (Struthio camelus var. domesticus) meat determine its nutritional importance for man. J. Anim. Sci. 73: 167-173.

DAFF (Department of Agriculture, Forest and Fisheries), 2013. A profile of the South African ostrich market value chain. http://www.nda.agric.za/doaDev/sideMenu/Marketing/Annual\%20Publications/Commodity\%20Profiles/Livestock/O strich\%20Market\%20Value\%20Chain\%20Profile\%202013.pdf. Retrieved 2 July 2015.

Glatz, P., Miao, Z., Rodda, B. \& Wyatt, S., 2008. Effect of diets with different energy and protein levels on performance of grower ostriches. Anim. Prod. Sci. 48,1338-1340.

Gous, R. \& Brand, T.S., 2008. Simulation models used for determining food intake and growth of ostriches: An overview. Anim. Prod. Sci. 48: 1266-1269.

Hoffman, L., 2012. Advances in the electrical stunning and bleeding of ostriches. Anim. Welfare. 21: 9-13.

Hoffman, L., Wolmarans, W., Smith, C. \& Brand, T., 2012. Effect of transportation on ostrich (Struthio camelus) weight loss and meat quality. Anim. Prod. Sci. 52: 1153-1162.

Hoffman, L.C., Joubert, M., Brand, T.S. \& Manley, M., 2005. The effect of dietary fish oil rich in $n-3$ fatty acids on the organoleptic, fatty acid and physicochemical characteristics of ostrich meat. Meat Sci. 70: 45-53.

Kritzinger, W.J., 2011. Allometric description of ostrich (Struthiocamelus var. domesticus) growth and development. MSc (Agric) thesis, University of Stellenbosch, South Africa.

Vecchiato, P., 2015. EU lifts four-year ban on fresh SA ostrich meat. http://www.fin24.com/Companies/Agribusiness/EUlifts-4-year-ban-on-fresh-SA-ostrich-meat-20150807. (Last accessed 11 November 2017). 